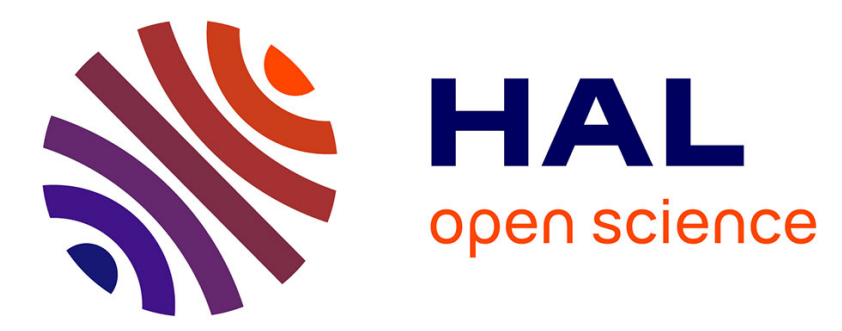

\title{
Continuous lipase esterification using process intensification technologies
}

Sébastien Elgue, Annelyse Conte, Alain A. Marty, Jean-Stéphane Condoret

\section{To cite this version:}

Sébastien Elgue, Annelyse Conte, Alain A. Marty, Jean-Stéphane Condoret. Continuous lipase esterification using process intensification technologies. Journal of Chemical Technology and Biotechnology, 2014, 89 (10), pp.1590-1598. 10.1002/jctb.4247 . hal-02640205

\section{HAL Id: hal-02640205 \\ https: / hal.inrae.fr/hal-02640205}

Submitted on 4 Oct 2021

HAL is a multi-disciplinary open access archive for the deposit and dissemination of scientific research documents, whether they are published or not. The documents may come from teaching and research institutions in France or abroad, or from public or private research centers.
L'archive ouverte pluridisciplinaire HAL, est destinée au dépôt et à la diffusion de documents scientifiques de niveau recherche, publiés ou non, émanant des établissements d'enseignement et de recherche français ou étrangers, des laboratoires publics ou privés.

\section{(c)(1)}

Distributed under a Creative Commons Attribution| 4.0 International License 


\title{
Continuous lipase esterification using process intensification technologies
}

\author{
Sébastien Elgue, ${ }^{a, b *}$ Annelyse Conté, ${ }^{a}$ Alain Marty ${ }^{c, d, e}$ and \\ Jean-Stéphane Condoret ${ }^{b}$
}

\begin{abstract}
BACKGROUND: Nowadays, developing continuous enzymatic processes, especially when a two-phase medium is required, remains a great challenge. So, there is a need to provide a technical solution for generating highly controlled interfacial area in a small volume. In this study, four types of reactors conventionally used for chemical process intensification and marketed by Corning, Chart Industries, NiTech Solutions and AM Technology, were tested for continuous lipase-catalysed esterification in two-phase medium.

RESULTS: The NiTech oscillating reactor proved to be the more efficient to transform the input mechanical power into mass transfer performance while proposing easily adjustable residence time. Nevertheless, Corning and Chart heat-exchanger reactors were shown to be very suitable candidates even if mass transfer performances depend on the flow-rate and therefore are not uncoupled from the residence time. This results in a less convenient choice of operating conditions. The Coflore system was not so convincing but it may be due to the injection device not well adapted to this system.

CONCLUSION: This work demonstrates that novel technologies, recently proposed for intensification of chemical processes, are indeed very suitable and provide a relevant alternative to conventional processes for enzymatic reactions and therefore for two-phase reactions limited by the interfacial area value. Also, it has been shown here that the model reaction considered could be a simple way to characterize mass transfer performances of these technologies.
\end{abstract}

Keywords: esterification; biocatalysis; lipase; process intensification; continuous reactor; two-phase reaction

\section{INTRODUCTION}

Operation of enzymatic reactions in two-phase medi, i.e. oil-water dispersions, is very common when hydrophobic reactants are concerned, as, for instance, in the case of hydrolysis of lipids. ${ }^{1,2}$ Moreover, reactions of synthesis, such as esterification, can also be effective in two-phase medium using free enzymes. ${ }^{3}$ Indeed, even in a two-phase system with a water activity close to unity, a shift of the thermodynamic equilibrium is obtained by maintaining a low ester activity. Initial laboratory studies are usually done in twophase media because enzymes are produced in aqueous phases. In this case, to assess the influence of operating conditions, such as reactant and catalyst concentrations, optimal temperature and $\mathrm{pH}$, batch experiments are done in a stirred vessel. Special care is then necessary to generate reproducible and well characterized liquid-liquid dispersion, in order to prevent erroneous conclusions due to uncontrolled changes in the contact area between phases. This is a crucial point, especially when reactions are limited by the interfacial area, which is the case when very active lipases are operated at the liquid-liquid interface. Note that such a problem is also encountered during liquid-liquid chemical reactions. When industrial development is envisaged, continuous operation must be considered in order to increase productivity and economic viability. But, at the present time, it is not possible to propose a realistic continuous liquid-liquid reactor where controlled contact area and steady operation are ensured. So, usually, to overcome this technical difficulty and make the most efficient and economic use of the enzyme, this latter is used as an immobilized biocatalyst packed in a tubular reactor. ${ }^{1,4,5}$ This implies correlative studies to provide an efficient immobilization method and is a handicap in terms of catalyst price and time for development. So, there is a need for a technical solution which makes it possible to directly use aqueous enzyme solutions in a continuous reactor, where the two-phase system is well controlled in terms of interfacial area and steadiness of operation. This kind of reactor will be efficient and attractive as it is able to provide a large controlled interfacial area in a small volume, i.e. a dense dispersion of small droplets. This

\footnotetext{
* Correspondence to: S. Elgue, MEPI - Plate-forme SAFRAN-HERAKLES, Chemin de la Loge, CS 27813, 31078 Toulouse Cedex 4, France. E-mail: sebastien.elgue@ensiacet.fr

a MEPI - Plate-forme SAFRAN-HERAKLES, Chemin de la Loge, CS 27813, 31078 Toulouse Cedex 4, France

b Laboratoire de Génie Chimique, INP Toulouse, 4 allée Emile Monso, BP 84234, 31432 Toulouse Cedex 4, France

c Université de Toulouse; INSA, UPS, INP; LISBP, 135 Avenue de Rangueil, F-31077 Toulouse, France

d INRA, UMR792 Ingénierie des Systèmes Biologiques et des Procédés, F-31400 Toulouse, France

e CNRS, UMR5504, F-31400 Toulouse, France
} 
opens the field to the so-called 'intensified' reactors which is now an identified target for successful industrial development of new processes. Note that, if the interfacial area is made non-sensitive to the flow-rates of the two phases, then the reactor technology becomes very attractive.

The aim of this study is to consider the use of several intensified reactor technologies, already existing at commercial scale, to operate enzymatic two-phase reactions. In order to focus on the reactor performance assessment of candidate technologies will be done using a model reaction, the lipase-catalysed esterification of oleic acid with ethanol. In addition to provide a technical solution, such an approach could also be considered as benchmarking for the different intensified reactor technologies.

For multi-phase applications, flow reactors allow enhanced mass transfer and controlled interfacial area, providing reproducible and reliable operation. From a technical viewpoint, flow reactors can be classified into two broad categories:

- Static mixing devices rely on motion of the fluid through the reactor to generate mixing effects and phase dispersion (in twophase systems). The most common type is the tubular reactor. Heat-exchanger reactors also belong to this category.

- Dynamic mixing devices where, by contrast, mixing is carried out using mechanical energy input done by different systems like in the most common type, the continuous stirred tank reactor, where mixing is obtained by the use of mechanical stirrers.

A detailed technological description of the different reactors is given in the Material section.

\section{MATERIAL AND METHODS \\ Materials}

Commercial liquid form of lipase B from Candida antarctica, namely Lipozyme CALB L, was a gift from Novozymes (Bagsvaerd, Denmark). Its concentration is $5000 \mathrm{LU} \mathrm{g}^{-1} .90 \%$ pure oleic acid was purchased from Sigma Chemical Co. (St. Louis, MO, USA). All other chemicals and solvents (ethanol, cyclohexane, and heptane) were of the highest purity and were purchased from Acros Organics (Geel, Belgium).

\section{Description of the reactors}

For each type of flow reactor two commercial solutions were considered here. The ability to carry out two-phase reactions and the technological maturity has driven the choice of these technologies. Hence, two heat-exchanger reactors commercialized by Corning and Chart Industries, and two examples of dynamic mixing devices the NiTech Solutions $\mathrm{COBR}^{\mathrm{TM}}$ and the AM Technology Coflore ${ }^{\circledR}$ were studied. It has been chosen to work on pilot scale versions of these equipments in order to be able to easily extrapolate the process to industrial scale. The four technologies tested are described below.

\section{Corning advanced-flow ${ }^{T M}$ reactor (AFR)}

The Corning Advanced-Flow ${ }^{\mathrm{TM}}$ glass reactor is an assembly of glass fluidic modules connected together using appropriate piping and connectors (Fig. 1). These fluidic modules are based on the plate heat-exchanger concept, in the form of a plate with fluidic channels that have a hydraulic diameter of around $2 \mathrm{~mm}$ and a volume around $10 \mathrm{~mL}$ per plate (at pilot scale: Gen 1). The plate is sandwiched between two heat exchange plates, thus providing efficient heat transfer performance. ${ }^{6,7}$ This configuration has been proved to enable operation with multiphase systems, as described in the literature. 8,9

To ensure good mixing and enhanced mass transfer performance, the fluidic channels exhibit specific designs and are adapted for the targeted application with respect to flow-rates and physical properties of fluids The efficiency of such complex designs inevitably induces significant pressure drop. Therefore, and because the stacking of plates is only able to withstand around 20 bar, this maximum pressure drop value limits the length of the reactor and therefore the residence time. So, in this kind of reactor, 15 to 20 min residence time can be considered a maximum (corresponding to a few hundred millilitres reactor volume). Thus, reaching high conversion level for the reaction could be challenging with regard to this limitation.

\section{Chart Industries Shimtec ${ }^{\circledR}$ reactor}

Chart Industries Shimtec ${ }^{\circledR}$ reactors are also based on the plate heat exchanger concept. The reactor is composed of three plates: one process plate sandwiched between two utility plates. The typical module presents similar characteristics to the Corning AdvancedFlow $^{\mathrm{TM}}$ reactor, with hydraulic diameter of about $2 \mathrm{~mm}$ and total process volume of around $15 \mathrm{~mL}$. Fluidic channels exhibit a specific design to ensure significant heat and mass transfer performance, ${ }^{10}$ particularly in the case of multi-phase applications. ${ }^{11}$

Shimtec ${ }^{\circledR}$ reactors are manufactured as a metallic complex frame made either with aluminium, stainless steel or special metals, depending on temperature, pressure and corrosiveness (Fig. 1). Assembly by diffusion bonding strengthens the heat transfer efficiency and also provides good resistance to pressure (of about 70 bar). Thus, these modules are able to operate at high temperature and pressure conditions where significant residence time and conversion levels can be reached.

NiTech Solutions Continuous Oscillatory Baffled Reactor ${ }^{T M}\left(C O B R^{T M}\right)$ NiTech Continuous Oscillatory Baffled Reactor ${ }^{T M}\left(C\right.$ COBR $\left.^{T M}\right)$ technology consists of a tubular reactor including annular-baffles (Fig. 1). Based on the principle of dynamic mixing devices, the performance is governed by the combination of flow-rate and fluid oscillations across these baffles via a piston system. The mixing mechanism in a baffled cell occurs in two steps (upstroke and downstroke) creating very efficient mixing and generation of a high interfacial area. ${ }^{12,13}$

The $\mathrm{COBR}^{\mathrm{TM}}$ used for this study is a pilot scale version of the reactor, based on $15 \mathrm{~mm}$ diameter jacketed glass tubes for $51 \mathrm{~m}$ total length and about $9 \mathrm{~L}$ total volume. As performance is decoupled from fluid velocity (i.e. flow-rate) thanks to the oscillation system, this reactor makes it possible to reach significantly longer residence times (in the range of hours) and so appears to be an interesting candidate for performing moderately fast reactions.

\section{AM Technology Coflore ${ }^{\circledR}$}

Coflore ${ }^{\circledR}$ reactors are multi-stage flow reactors that deliver good mixing and transfer performance through the concept of dynamic mixing. In fact, the Coflore ${ }^{\circledR}$ design implements a mixing technique where free moving agitators within each reaction cell promote mixing when the reactor body is subjected to lateral shaking (Fig. 1). This generates intense mixing without high flow velocity or the need for rotating shafts with mechanical seals or 

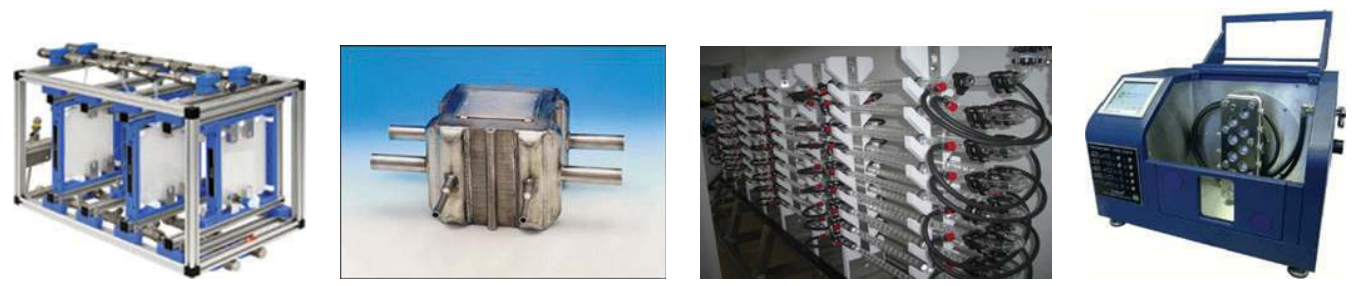

Figure 1. Flow reactors considered, from left to right: Corning Advanced-Flow ${ }^{\mathrm{TM}}$, Chart Shimtec ${ }^{\circledR}$, NiTech $\operatorname{COBR}^{\mathrm{TM}}$ and $A M$ Technology Coflore ${ }^{\circledR}$.

mixing baffles and offers the possibility to reach long residence times.

The Coflore ${ }^{\circledR}$ used during this study is a pilot scale version of the reactor: the ACR. It uses high shear agitators in reaction cells and has a working capacity of $100 \mathrm{~mL}$. The enhanced mixing and transfer performances of this reactor for multi-phase systems have been demonstrated. ${ }^{14}$ Also work on biocatalysis application ${ }^{15}$ has been reported, offering interesting perspectives for lipase catalyzed esterification.

\section{Description of the reaction}

The chosen reaction is a model reaction, the lipase-catalysed esterification with ethanol $\left(300 \mathrm{mmol} \mathrm{L}^{-1}\right)$ of a fatty acid, oleic acid $\left(100 \mathrm{mmol}^{-1}\right)$, to yield ethyloleate and water (Equation (1)).

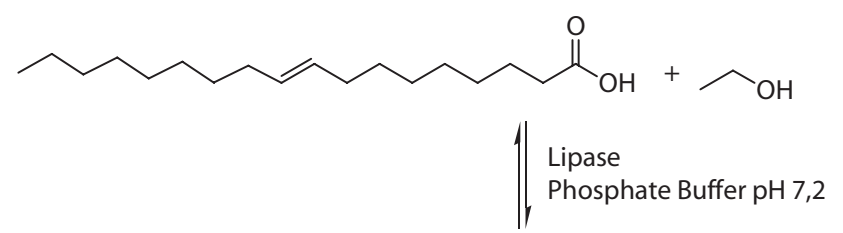

乎

To catalyse this esterification, the commercial liquid form of lipase B from Candida antarctica, namely Lipozyme CALB L, was chosen. To obtain an enzyme activity in agreement with the residence times envisaged in the continuous process, commercial enzyme solution was 50 or 100 times diluted in a phosphate buffer $0.1 \mathrm{~mol} \mathrm{~L}^{-1}, \mathrm{pH} 7.2$ to reach an activity of 100 or $50 \mathrm{LU} \mathrm{g}^{-1}$.

Esterifications are equilibrated reactions and the equilibrium constant is given by the following equation:

$$
K e q=\frac{a_{\text {ester eq }} \cdot a_{w e q}}{a_{\text {acid eq }} \cdot a_{\text {alcohol eq }}}
$$

where $a_{i e q}$ are the thermodynamic activity of component $i$ in the fluid phases at equilibrium. To shift the reaction towards synthesis, it is necessary to maintain the numerator of the equation as low as possible and the denominator as high as possible. In a twophase system, water activity is close to unity $\left(a_{w}=1\right)$ which is very unfavourable for esterification reactions. Nevertheless, the reaction is shifted towards esterification because the hydrophobic ester accumulates in the solvent which plays the role of a reservoir for the most hydrophobic reactant, the ester. In other words, the solvent maintains at a low value the thermodynamic activity of the ester. In this work, cyclohexane was used to play this role.

The lipase-catalysed esterification of oleic acid with ethanol has been studied at pilot scale, which means that the total flow-rate (i.e. the sum of the flow-rates of both phases) is in the range 15 to $150 \mathrm{~g} \mathrm{~min}^{-1}$. A specific fluidic module has been used to control the feeding of raw solutions and the temperature of the process.
The fluidic module is constituted of two dosing lines composed of micro-annular gear pumps (HNP Mikrosysteme - mzr series), mass-flow meters based on the Coriolis effect (Micromotion - elite series) and temperature and pressure sensors. PID controllers ensure constant delivery of flow-rates by acting on the motor pump regime. Special care has been taken to prevent pulsating flow-rates, especially in the case of NiTech COBR ${ }^{T M}$. This is done by using a combination of check and safety valves set on the dosing lines to prevent piston pulsation from disturbing the pump flowrates. A process-thermostat (Lauda integral XT 150) is associated with the fluidic module to control the process temperature. All operating parameters (temperature, pressure, flow-rate) are online, recorded using a computer.

Whatever flow-reactor is considered, the process is based on the flow-sheet of Fig. 2. The organic phase composed of cyclohexane, oleic acid and ethanol and the aqueous phase composed of lipase diluted in a phosphate buffer solution are respectively introduced by dosing lines 1 and 2. To obtain isothermal profiles and then make accurate comparisons, feed flows are pre-heated or pre-cooled, depending on the operating temperature, thanks to the first set of Corning DTR microstructures. Then both phases are introduced inside the selected reactor (Corning Advanced-Flow ${ }^{\mathrm{TM}}$ reactor in the case of Fig. 2). Temperature sensors are set along the reactor path and allow measurement of temperature profiles. Because of the absence of thermal effects from the enzymatic reaction, we never observed temperature variation in the temperature profile throughout the reactor for all our experiments, whatever the technology tested. A sampling valve is located at the reactor outlet to estimate the final conversion using HPLC chromatography analysis.

\section{Analysis of reaction evolution}

Samples collected at the output of the reactor are centrifuged to separate the heavy enzyme aqueous phase from the organic one containing non-reacted substrate and product. Then, organic solution is evaporated to eliminate the solvent, and the concentrated mixture is diluted with HPLC mobile phase.

Analysis of oleic acid and ethyloleate concentrations is done using a THERMO Accela 600 apparatus, equipped with a Refractive Index Detector. A Waters C18 column $(250 \times 4.6 \mathrm{~mm}, 3.5 \mu \mathrm{m}$ particle size) is used. The mobile phase is Methanol (HPLC quality) with $0.02 \%$ vol. of pure acetic acid. An isocratic flow-rate of

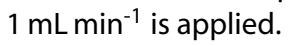

\section{RESULTS}

\section{Study of the esterification using batch reactors}

In order to have a reference value, batch esterification reactions were performed in small Eppendorf tubes agitated in a Vortex. The reaction was carried out at room temperature in $1.5 \mathrm{~mL}$ Eppendorf tubes containing $0.5 \mathrm{~mL}$ of organic phase and $0.5 \mathrm{~mL}$ of aqueous 


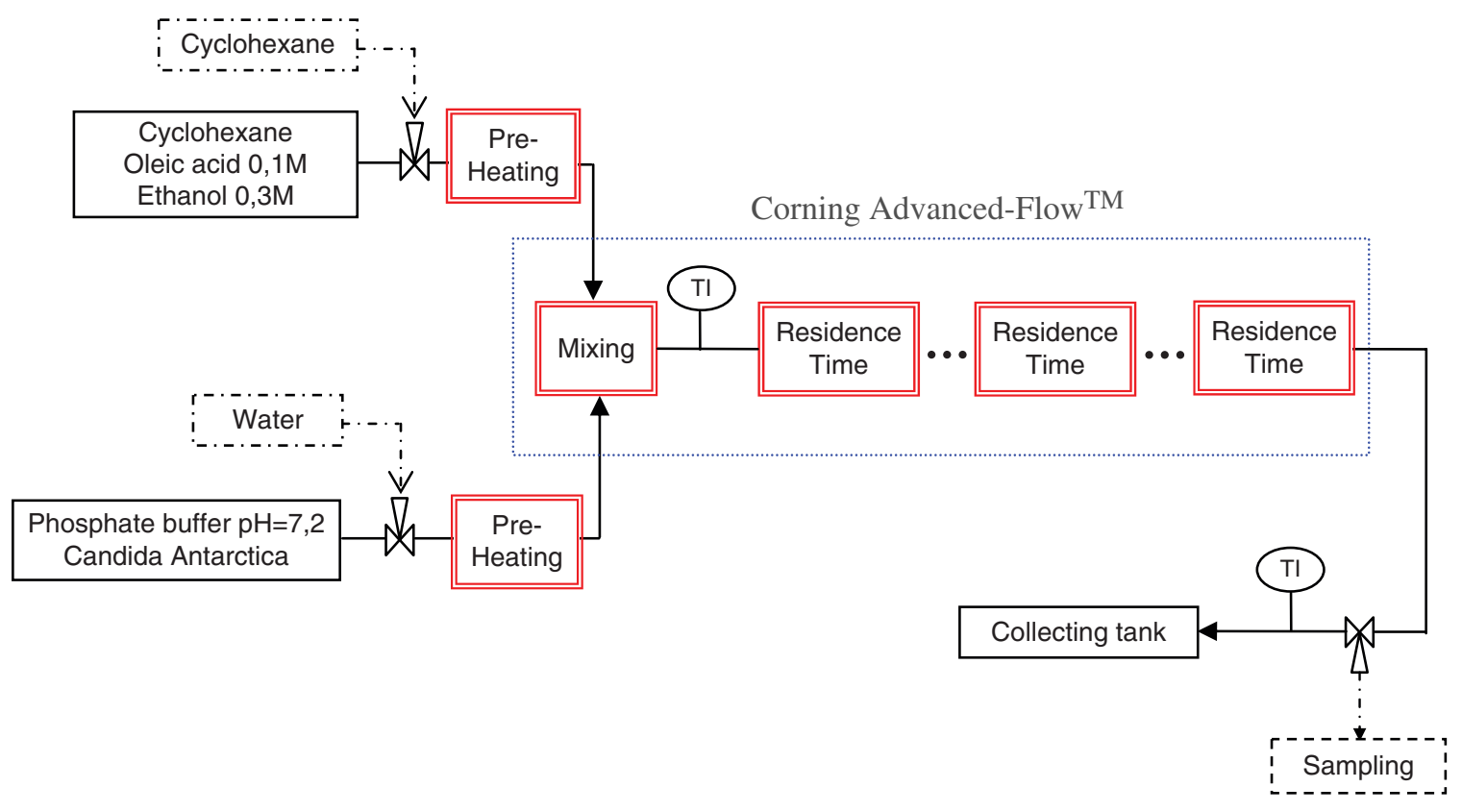

Figure 2. Flow-sheet of the continuous esterification process, based on the use of Corning Advanced-Flow ${ }^{\mathrm{TM}}$ reactor.

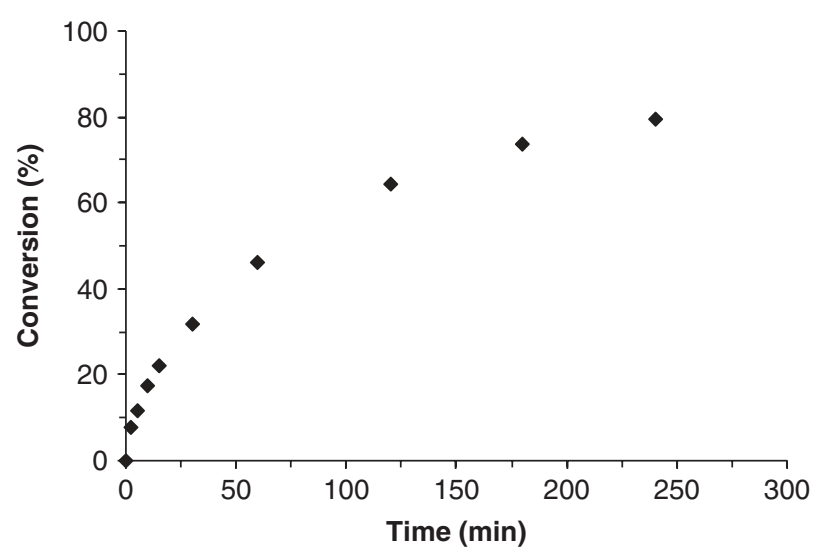

Figure 3. Batch esterification in a laboratory scale reactor $(1 \mathrm{~L})$. Volumic ratio between organic and aqueous phase is 1 . EtOH/Oleic acid molar ratio is 3. Temperature is $30^{\circ} \mathrm{C}$. Lipase concentration is $50 \mathrm{LU} \mathrm{g}^{-1}$.

enzymatic solution. The mixture was shaken in a Vortex Genie 2 (D. Dutscher, Brumat, France). The progress of the reaction was followed at regular time intervals by taking samples from the organic phase. $90.4 \%$ conversion was obtained within 30 min (data not shown). In addition, to make the comparison as complete as possible, the esterification was carried out in a standard glass reactor at lab scale $(1 \mathrm{~L}$, double jacketed with impeller stirring device) at optimal stirring velocity (360 rpm). In that case (Fig. 3), the operating conditions were chosen to be comparable with those applied in the different continuous reactors.

Batch study shows that initial velocity is 6 times lower in the batch laboratory scale reactor than in small eppendorf tubes, demonstrating the influence and the limitation of mass transfer during this reaction in a two-phase medium.

\section{Study of the esterification using static mixing flow reactors} In flow reactors based on the static mixing concept, performances are driven by flow velocity: an increase of flow-rate favours the generation of interfacial area and therefore mass transfer. Also, as reactor volume is fixed, increasing flow-rate reduces the residence time. Consequently, in the case of two-phase reactions, depending on the primary reaction regime (kinetic, mass transfer or transitional regime), there is an optimal flow-rate leading to the highest conversion level. To validate these assumptions, a study of the total flow-rate influence was carried out in Corning and Chart flow reactors. Recall that total flow-rate is defined as the sum of organic and aqueous phase flow-rates. The flow-rate of each phase can be deduced from the mass ratio (given in Table 1). The operating conditions and the associated results are detailed in Table 1 and Fig. 4, respectively.

The evolution of conversion with respect to global flow-rate in the Corning reactor exhibits a flat bell-shaped curve. At low flow-rates (lower than $105 \mathrm{~g} \mathrm{~min}^{-1}$ ), conversion is increasing due to improved mixing performances and interfacial area generation, despite the reduction of global residence time (defined as the reactor volume divided by the total flow-rate). At higher flow rates, the conversion decreases because the reduction of the residence time is more detrimental than the gain in mass transfer which moreover will reach an upper limit. Unfortunately, because of the high pressure drop involved at high flow-rates, due to the limitation of dosing line pumps, it was not possible to experimentally observe such behaviour.

In the range of flow rates tested, for the Chart reactor, mixing improvement and residence time reduction seem to counterbalance. This is in agreement with the fact that the Chart reactor offers better mass transfer performance at low flow-rates. As a consequence, the maximum conversion (around 25\%) was reached for different values of flow-rate. Therefore, to determine the optimal flow-rate, additional criteria should be defined, for instance in terms of productivity or power consumption. Indeed, high flow rates resulted in better productivity but high power consumption because the pressure drop was larger.

To discriminate the reactors from an industrial viewpoint, it is relevant to represent the conversion with respect to the energy dissipation rate, as presented in Fig. 5 . Such computation is easily 
Table 1. Operating conditions of esterification in flow reactors

\begin{tabular}{lcccc}
$\begin{array}{l}\text { Global } \\
\text { flow-rate }\left(\mathrm{g} \mathrm{min}^{-1}\right)\end{array}$ & $\begin{array}{c}\text { Volumic ratio } \\
(\varphi \text { organic } / \varphi \text { aqueous })\end{array}$ & $\begin{array}{c}\text { Mass ratio } \\
(\varphi \text { organic } / \varphi \text { aqueous })\end{array}$ & $\begin{array}{c}\text { Lipase } \\
\text { Temperature }\left({ }^{\circ} \mathrm{C}\right)\end{array}$ & $\begin{array}{c}\text { EtOH/Oleic } \\
\text { concentration }\left(\mathrm{LU} \mathrm{g}^{-1}\right)\end{array}$ \\
\hline From 15 to 150 & 1 & 0.78 & 30 & 100
\end{tabular}

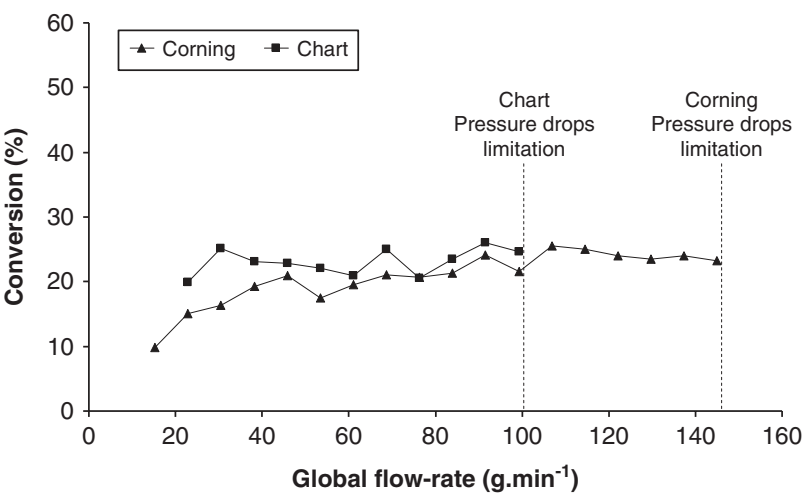

Figure 4. Influence of total flow-rate on conversion for Corning and Chart flow reactors. See Table 1 for conditions.

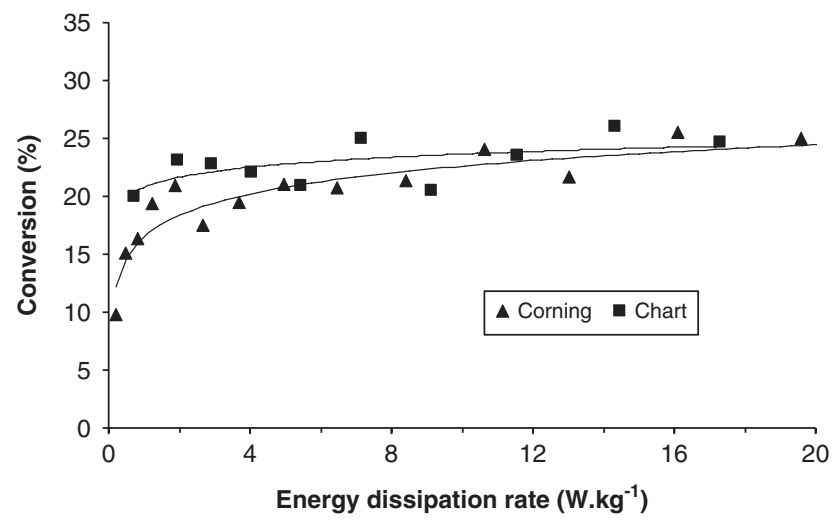

Figure 5. Conversion obtained in flow reactors according to energy dissipation rate See Table 1 for conditions.

done for reactors based on the static mixing concept where the energy dissipation rate is related to flow-rate and pressure drop, according to the following equation:

$$
\epsilon=\frac{Q \times \Delta P}{\rho \times V}
$$

with $\epsilon$ the energy dissipation rate $\left(\mathrm{W} \mathrm{kg}^{-1}\right), Q$ the volume flow-rate $\left(\mathrm{m}^{3} \mathrm{~s}^{-1}\right), \Delta P$ the pressure drop $(\mathrm{Pa}), \rho$ the reactive medium density $\left(\mathrm{kg} \mathrm{m}^{-3}\right)$, and $V$ the volume of the reactor $\left(\mathrm{m}^{3}\right)$.

Again this comparison highlights the better performance of the Chart technology and its ability to reach a given conversion level with reduced energy dissipation rate, i.e. less power consumption.

Different parameters have to be investigated to compare the associated behaviours of the Corning and Chart reactors. In this way, the influence of temperature, lipase concentration and substrate ratio were studied. These studies were performed at a total flow-rate of $46 \mathrm{~g} \mathrm{~min}^{-1}\left(20 \mathrm{~g} \mathrm{~min}^{-1}\right.$ of organic phase, $26 \mathrm{~g} \mathrm{~min}^{-1}$ of aqueous phase), which corresponds to a total residence time of $140 \mathrm{~s}$.

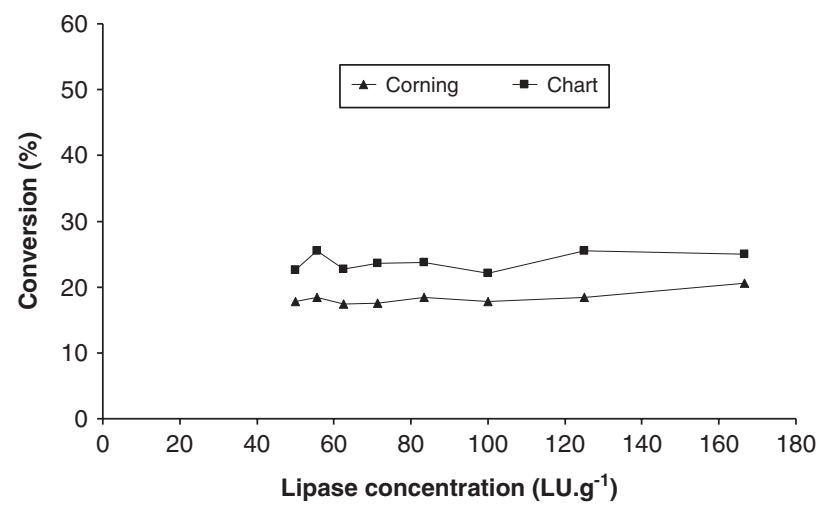

Figure 6. Evolution of conversion according to lipase concentration with $140 \mathrm{~s}$ residence time. Volumic ratio between organic and aqueous phase is equal to 1 . EtOH/Oleic acid molar ratio of 3. Temperature is $30^{\circ} \mathrm{C}$.

\section{Influence of lipase concentration}

As seen in Fig. 6, the performances are rather insensitive to this parameter. It can be postulated that the reaction is taking place only at the interface where lipases are concentrated and where hydrophobic substrates in the organic phase can access their active site, which is directed towards the organic phase. Indeed, lipases are known to be active at the interface. ${ }^{16}$ When saturation of the interface is reached, the concentration of the biocatalyst at the interface is no longer dependent on its concentration in the aqueous phase, and therefore the kinetics is insensitive to this parameter as is observed here. This means that the reaction is governed mainly by the interfacial area value. This is an interesting result because it enables one to define a minimal quantity of lipases to be used. Operating at minimum biocatalyst quantity is favourable for the economics when such a process is envisaged at production scale.

In addition, from the point of view of comparing different technologies, this makes it possible to discriminate them in terms of creating and maintaining interfacial area.

\section{Influence of temperature}

Chart and Corning reactors exhibit high heat transfer performance ${ }^{17}$ which lead to an isothermal profile of the reactive medium temperature. Thermocouples located along the channel validated this statement. Therefore, it appears relevant to study the influence of temperature on conversion, as shown on Fig. 7.

It is seen in Fig. 7 that, up to $50^{\circ} \mathrm{C}$, temperature has a slight positive influence on conversion. Then a decrease of conversion is seen which can probably be attributed to deactivation of the enzyme. Indeed, it is known that operating at high temperature very often leads to enzyme denaturation.

The first increasing part of the curve is more difficult to understand. It is very moderate and do not correspond to a plain kinetic increase. Indeed, kinetics is very sensitive to temperature and a $30^{\circ} \mathrm{C}$ temperature rise should have resulted in a more significant conversion gain (from a very conventional exponential Arrhenius 


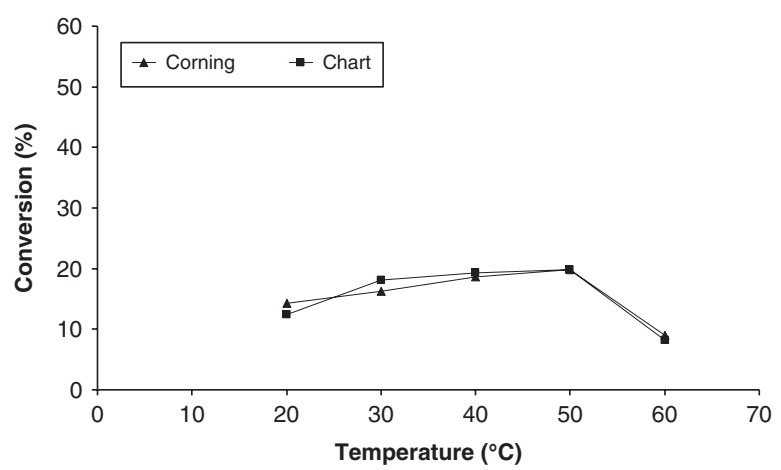

Figure 7. Evolution of conversion according to temperature with $140 \mathrm{~s}$ residence time. Volumic ratio between organic and aqueous phase is equal to 1. EtOH/Oleic acid molar ratio of 3. Lipase concentration $100 \mathrm{LU} \mathrm{g}^{-1}$.

law). In our previous analysis of the lipase concentration influence, it was shown that the liquid-liquid interface was probably saturated with lipases and that the apparent kinetics was dependent only on the interfacial area at a given temperature. Nevertheless, the interfacial kinetics should remain temperature sensitive.

So, an explanation could be that interfacial kinetics is very fast and that the phenomenon is mass transfer limited. Indeed, in this case the moderate conversion increase is in accordance with usual mass transfer enhancement by temperature. So, the weak gain in conversion can be attributed to enhancement of the diffusion of the limiting substrate, probably oleic acid, towards the interface. Nevertheless, it can also be hypothesized that increase of temperature has favourably modified certain physical properties, such as viscosity or interfacial tension, that has led to a moderate increase of the liquid-liquid dispersion, and therefore of the interfacial area. Also, this ascertains that value of conversion for this reaction is a direct assessment of the mass transfer performances of the technology. It is not really possible to uncouple the diffusion effects from the interfacial area effect, as is often the case in chemical engineering where these effects are usually gathered in the global concept of volumetric mass transfer coefficient $k_{L} a$.

\section{Influence of substrate ratio}

Substrate ratio is defined as the ratio of ethanol concentration to oleic acid concentration in the initial organic phase, this latter being fixed at 3 .

Regarding substrate molar ratio (Fig. 8), two zones have to be considered. First, increasing the substrate ratio, i.e. using excess of alcohol, leads to better conversion $(+5 \%$ in the Corning reactor from 3 to 6 molar eq.; $+10 \%$ in the Chart reactor from 3 to 10 molar eq.) due to the increased availability of ethanol for the reaction. Then, higher values induce the opposite effect and conversion decreases. This decrease is in accordance with the mechanism of such reactions which was demonstrated to be a Ping Pong $\mathrm{Bi} \mathrm{Bi}$ mechanism where ethanol is a competitive inhibitor. ${ }^{18}$

As was mentioned in the case of the temperature effect, the initial moderate effect is not due to a kinetic effect but here also to mass transfer enhancement. More precisely in this case, this effect is probably mainly due to interfacial area enhancement. Indeed, increasing ethanol concentration reduces the surface tension of the water-ethanol mixture and therefore droplet size. Recall that ethanol partitions very favourably into the aqueous phase.

For these two flow reactors, this parametric study has shown that, in spite of a possible optimization, the antagonism between

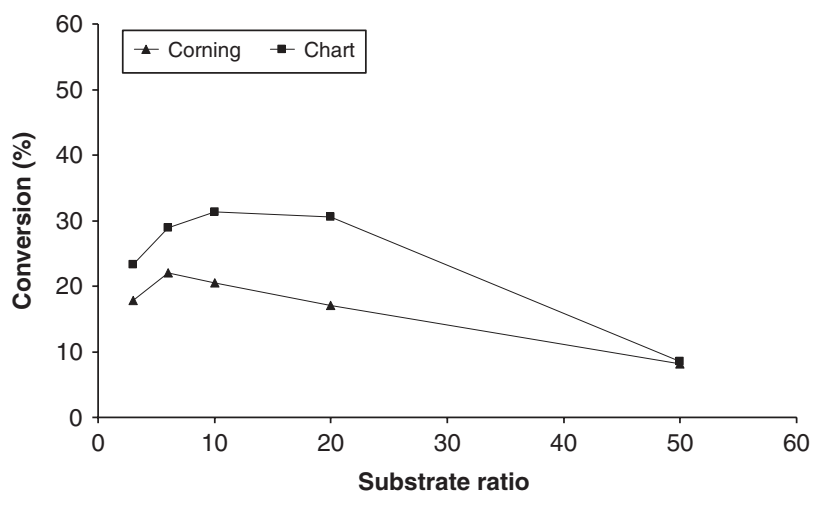

Figure 8. Evolution of conversion according to substrate ratio with $140 \mathrm{~s}$ residence time. Volumic ratio between organic and aqueous phase is equal to 1. Lipase concentration is $100 \mathrm{LU} \mathrm{g}^{-1}$ and temperature is $30^{\circ} \mathrm{C}$.

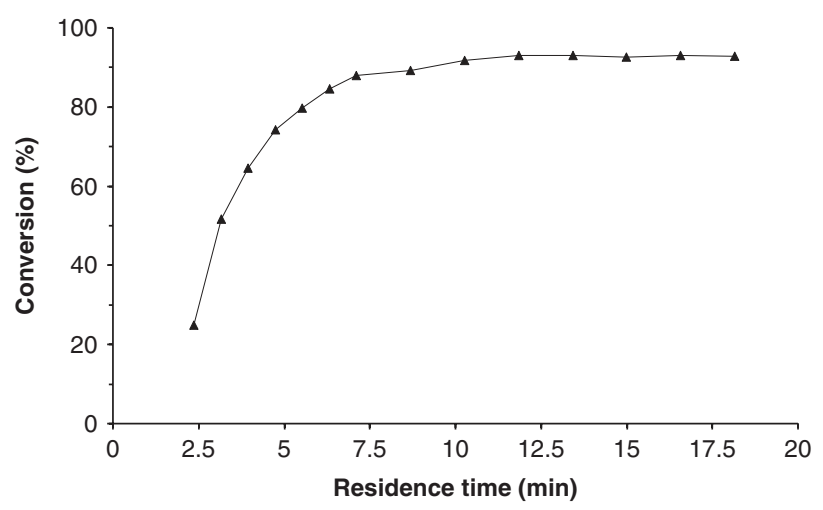

Figure 9. Esterification using recycled-loop mode in Corning reactor with total flow-rate of $46 \mathrm{~g} \mathrm{~min}^{-1}$. Volumic ratio between organic and aqueous phase is 1. Substrate ratio is 6 . Lipase concentration is $50 \mathrm{LU} \mathrm{g}^{-1}$ and temperature is $50^{\circ} \mathrm{C}$.

residence time/mass transfer did not enable high conversion levels to be reached in open-loop operation, i.e. with only one pass in the reactor. To estimate the residence time required to obtain high conversion, recycled-loop experiments were carried out. In such experiments, the flow at the reactor outlet was instantaneously collected in a cooled stirred vessel (to quench the reaction and maintain dispersion) and reintroduced at the reactor inlet via a dedicated pump. These operations were performed with special care to avoid disturbing the reactive system and to yield accurate residence time estimation.

Recycled-loop experiments were carried out in both reactors at the previously used global flow-rate of $46 \mathrm{~g} \mathrm{~min}^{-1}$. Operating conditions were optimized according to the previous parametric studies in order to increase reaction kinetics $\left(50^{\circ} \mathrm{C}\right.$, substrate ratio =6). Results shown in Fig. 9 emphasize clearly the possibility of reaching high conversion levels (almost 100\%) with moderate increase of residence time (about $600 \mathrm{~s}$ instead of $140 \mathrm{~s}$ in the onepass experiment). Compared with the initial 140 s residence time, this means that such residence times can be easily obtained by using reactors with larger volumes (3-4-fold increase). Indeed, such values fully comply with residence time values usually available in Corning or Chart flow reactors. This definitely validates the possibility to operate lipase-catalysed esterification in openloop intensified flow-reactors. Note that a correlative increase of the pressure drop and therefore of the power consumption must also be taken into account. 


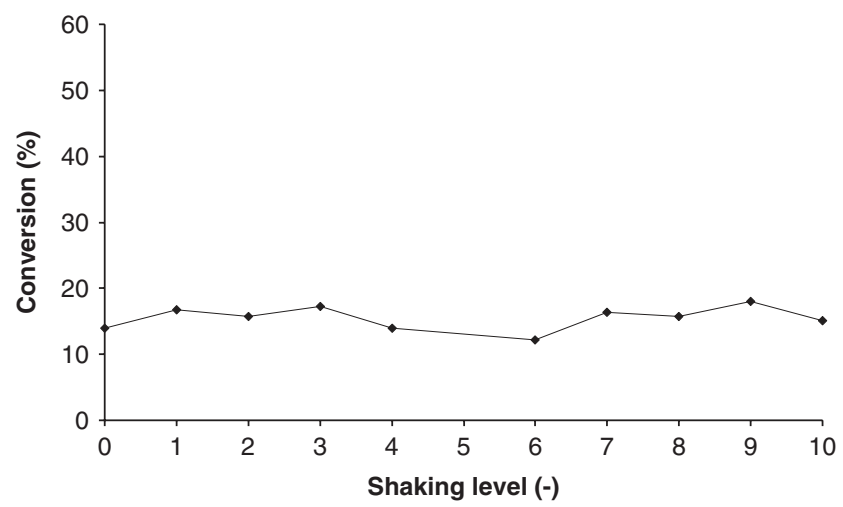

Figure 10. Evolution of conversion according to shaking power in Coflore ${ }^{\circledR}$ with a residence time of $140 \mathrm{~s}$. Substrate ratio $=3$. Volumetric ratio between organic and aqueous phase is equal to 1 . Lipase concentration is $100 \mathrm{LU}$ $\mathrm{g}^{-1}$ and temperature is $30^{\circ} \mathrm{C}$.

\section{Esterification study in AM Technology Coflore ${ }^{\circledR}$}

The concept of Coflore ${ }^{\circledR}$ reactors, based on dynamic mixing through lateral shaking and free moving agitators, appears particularly suited to two-phase applications. Literature emphasizes the intense mixing performances of such equipment ${ }^{14}$ and the related advantages for a biocatalysis application. ${ }^{15}$

In spite of all this favourable background, in the device tested here, the results of lipase-catalysed esterification were rather disappointing compared with the other continuous reactors. In fact, under the same operating conditions and particularly the same global residence time ( $140 \mathrm{~s}$, same mass ratio), the conversion was about $15 \%, 5 \%$ less than in static mixing flowreactors, independently of the shaking graduation on the device (i.e. the power allocated for mixing) (Fig. 10).

Indeed, visual observation during the experiments showed that it was not possible to obtain or maintain liquid-liquid dispersion at the reactor outlet. A posteriori, the lower conversion obtained tends to demonstrate that no efficient liquid-liquid dispersion was created inside the reactor, thus limiting the mass transfer performance. In this type of flow reactor, two parameters contribute to the creation of liquid-liquid dispersion: the injection system generally based on nozzles and the specific mixing performances of the device. The injection system used in this study was probably not well-designed with respect to the characteristics of the two-phase system involved here, in terms of physical properties (density, viscosity, interfacial tension) and phase ratio (aqueous vs. organic).

In the context of this work, for this specific device, it was neither possible to test different injection systems nor possible to perform further investigations to improve the mass transfer performances. However, a parametric study focusing on the application parameters (temperature, ethanol ratio, etc.) has been realized, validating the same trends as in the previous static mixing devices.

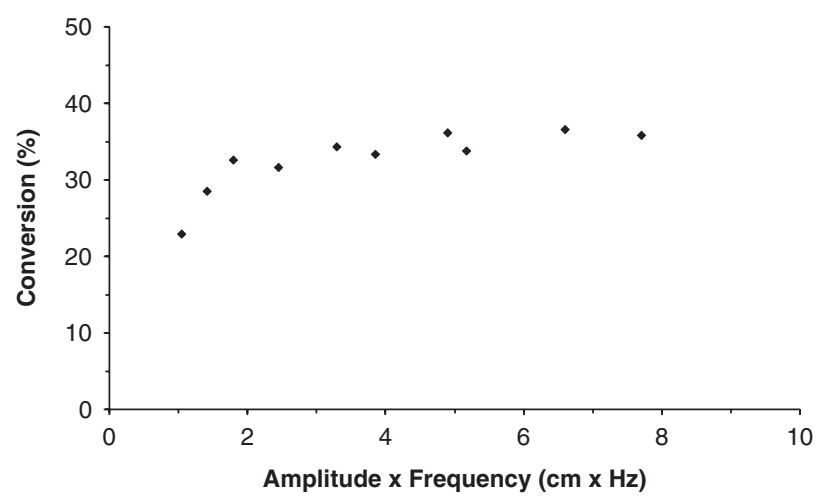

Figure 11. Evolution of conversion in $\mathrm{COBR}^{\mathrm{TM}}$ with respect to pulse characteristics See Table 2 for conditions.

\section{Esterification study in NiTech COBR ${ }^{\mathrm{TM}}$}

The equipment is a DN15 version of the reactor. This dimension and the associated nominal operating conditions increase the global flow-rate compared with the value required in Corning and Chart reactors. However, the length of the reactor has then been adapted to obtain the same $140 \mathrm{~s}$ residence time. The resultant conditions are given in Table 2 and are mainly based on the optimal conditions determined in previous flow-reactors.

It is important to note that the $\mathrm{COBR}^{\mathrm{TM}}$ then allows higher conversion level (about 40\%) to be reached for the same given $140 \mathrm{~s}$ residence time. From its technical principle, the velocity in the NiTech reactor is low (about $0.01 \mathrm{~m} \mathrm{~s}^{-1}$ ) by comparison with Corning and Chart equipment (from 10 to 100 times more: 0.1 to $1 \mathrm{~m} \mathrm{~s}^{-1}$ ), which entails poor mixing by the static mixing effect. As a consequence, the mass transfer performances are governed only by the pulsation, through its amplitude and frequency. The influence of such 'technological' parameters has been experimentally estimated and correlated with the product amplitude-frequency, as is usually done in the case of pulsed systems. Results are presented in Fig. 11.

As it was shown that the reaction occurs as a mass transfer regime, the pulsation, characterized by the product amplitude-frequency, has a direct effect on mass transfer and favours the conversion as observed on Fig. 11. Conversions as high as $35 \%$ are obtained, significantly better than for flow-reactors for the same residence time. In fact, this reactor, thanks to the pulsation system, improves greatly the mass transfer (mainly through greater interfacial area generation) in a range that could not be reached in static mixing based reactors, where a compromise between performance and residence time has to be considered.

It is important to note that increasing residence time in the $\mathrm{COBR}^{\mathrm{TM}}$ is easy. The total possible available length in our lab is $51 \mathrm{~m}$, which corresponds to more than $1 \mathrm{~h}$ with the operating conditions considered. For instance, with a residence time of $350 \mathrm{~s}$, conversion was found to be about $60 \%$. This offers interesting perspective when coupled with optimization of the reaction conditions

Table 2. Operating conditions of esterification in $\mathrm{COBR}^{\mathrm{TM}}$

\begin{tabular}{|c|c|c|c|c|c|}
\hline $\begin{array}{l}\text { Global } \\
\text { flow-rate }\left(\mathrm{g} \mathrm{min}^{-1}\right)\end{array}$ & $\begin{array}{c}\text { Volumic ratio } \\
(\varphi \text { organic } / \varphi \text { aqueous })\end{array}$ & $\begin{array}{c}\text { Mass ratio } \\
(\varphi \text { organic } / \varphi \text { aqueous })\end{array}$ & Temperature $\left({ }^{\circ} \mathrm{C}\right)$ & $\begin{array}{c}\text { Lipase } \\
\text { concentration }\left(\mathrm{LU} \mathrm{g}^{-1}\right)\end{array}$ & $\begin{array}{c}\text { EtOH/Oleic } \\
\text { Acid molar ratio }\end{array}$ \\
\hline 110 & 1 & 0.78 & 30 & 50 & 3 \\
\hline
\end{tabular}




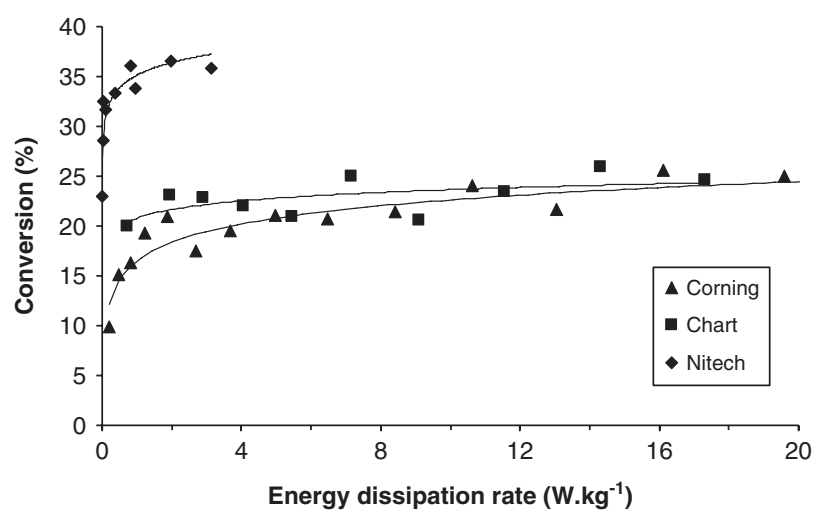

Figure 12. Conversion vs. energy dissipation rate for the different technologies See Table 1 and 2 for conditions.

(temperature, concentration, ethanol equivalent, volumic phase ratio, etc.)

Therefore, the COBR ${ }^{T M}$ appears to be a very interesting solution for two-phase applications, as it allows mass transfer performance to be enhanced independently of residence time. Nevertheless, the pressure drop involved with the pulsation system must be taken into account. Indeed, high mass transfer performances induce high cost in terms of pulsation power and energy consumption. To perform a comparison with static mixing based reactors (Corning and Chart), the energy dissipation rate in the COBR ${ }^{T M}$ was computed. To achieve this, the evaluation method for power dissipation in pulse columns proposed by Jealous and Johnson ${ }^{19}$ was used (Equation (4)). In this approach, the energy dissipation due to the net flow in the $\mathrm{COBR}^{\mathrm{TM}}$ is neglected and the total energy dissipation depends only upon amplitude and frequency of the pulsation.

$$
\epsilon=\frac{16 \pi^{2} N}{3 C_{d}^{2}} \frac{\left(1-T^{2}\right)}{T^{2}}\left(x_{0} f\right)^{3}
$$

with $\epsilon$ the energy dissipation rate $\left(\mathrm{W} \mathrm{kg}^{-1}\right), N$ the number of baffled cells per unit length $\left(\mathrm{m}^{-1}\right), C_{d}$ the orifice coefficient for the flow through the baffle hole; $T$ the fractional free area defined as the ratio between orifice and tube diameter, $x_{0}$ the amplitude defined centre-to-peak $(\mathrm{m})$, and $f$ the oscillation frequency $(\mathrm{Hz})$.

The curves of Fig. 11 are redrawn in terms of energy dissipation rate in Fig. 12, where it is seen that the NiTech reactor provides the best use of energy dissipation.

\section{Benchmarking}

The results obtained on different equipments and under different operating conditions lead to the same conclusions: lipase catalysed esterification is limited by mass transfer. So as we mentioned in the introduction, the operation of this model reaction using these different technologies can also be considered as an assessment of the mass transfer performance of each reactor, especially in terms of generation of interfacial area. As the products and the reaction involved here are easy to carry out, this constitutes an excellent test to characterize mass transfer performance of different devices. Indeed, benchmarking of equipments could be performed in this way. This was done for the different equipments considered in the present work. A given $140 \mathrm{~s}$ total residence time was chosen and other parameters are given in Table 3. For dynamic mixing devices, 'optimal' operating conditions have been chosen as being those leading to the maximum conversion: optimal shaking for Coflore ${ }^{\circledR}$, optimal amplitude and frequency for $\mathrm{COBR}^{\mathrm{TM}}$.
Table 3. Operating conditions applied for benchmarking

\begin{tabular}{|c|c|c|c|c|}
\hline Reactor & $\begin{array}{c}\text { Residence } \\
\text { time (s) }\end{array}$ & $\begin{array}{c}\text { Temperature } \\
\left({ }^{\circ} \mathrm{C}\right)\end{array}$ & $\begin{array}{c}\text { Lipase } \\
\text { concentration } \\
\left(\mathrm{LU} \mathrm{g} \mathrm{g}^{-1}\right)\end{array}$ & $\begin{array}{c}\mathrm{EtOH} / \\
\text { Oleic } \\
\text { Acid } \\
\text { molar } \\
\text { ratio }\end{array}$ \\
\hline $\begin{array}{l}\text { Batch } \\
\text { Corning AFR }\end{array}$ & & & & \\
\hline $\begin{array}{l}\text { Chart Shimtec }{ }^{\circledR} \\
\text { AMT Coflore }{ }^{\circledR} \\
\text { Nitech COBR }\end{array}$ & 140 & 30 & 50 & 3 \\
\hline
\end{tabular}

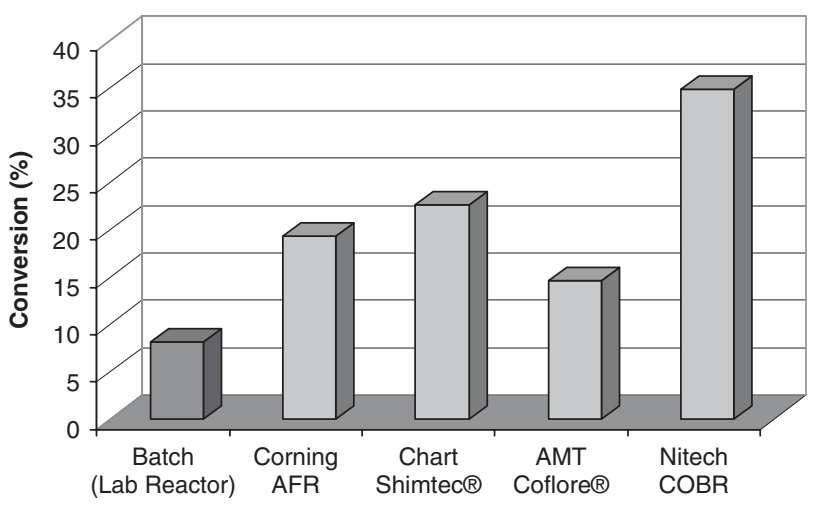

Figure 13. Benchmark of mass transfer performances See Table 3 for conditions.

Figure 13 illustrates the comparison of mass transfer performance of the different equipments operated at their optimum operating conditions and at the same $140 \mathrm{~s}$ residence time. As expected, NiTech COBR $^{T M}$ appears the most efficient. Moreover, in such a device the possibility to reach high residence times (up to $100 \mathrm{~min}$ ) also goes along with its enhanced mass transfer performance.

\section{CONCLUSION}

The main result of this work was to demonstrate that novel technologies, recently proposed for intensification of chemical processes, are indeed very suitable to operate two-phase reactions. This was tested on a model enzymatic reaction which represents an important class of enzymatic reactions where lipases are used for organic synthesis. Four commercial intensified reactor technologies were tested. The NiTech oscillating reactor proved to be the most efficient to transform the input mechanical power into mass transfer performance while enabling an easily adjustable residence time. Nevertheless Corning and Chart reactors were also shown to be very suitable candidates even though mass transfer performance depends on the flow-rate of the reacting mixture and therefore is not decoupled from the residence time. This last drawback results in a less convenient choice of operating conditions. The Coflore ${ }^{\circledR}$ system was not so convincing, possibly due to its injection device, which was probably not well adapted to this liquid-liquid system.

More generally, it was shown here that the usual technical drawback for operation of these reactions in two-phase systems, i.e. mastering the liquid-liquid dispersion, can be circumvented. 
This is very interesting because such a drawback usually directs the industrialization of such reactions towards the use of low productivity batch systems using large agitated tanks with uneasy control of the two-phase dispersion. Indeed, continuous operation using agitated tanks with two-phase systems is very difficult, especially because the phase ratio in the output flow must be carefully controlled to ensure steady operation. When efficient continuous operation is desired, this implies operating the reaction in a monophasic system in order to be able to use a continuous fixed bed of immobilized enzymes. As was mentioned in the introduction, additional R\&D studies are therefore needed, especially of complex immobilisation procedures, with a possible loss of activity. Conversely, using the new intensified reactor technologies proposed here, direct extrapolation to continuous steady operation of a two-phase enzymatic reaction at industrial scale is really possible.

Nevertheless, each two-phase system is unique and has a specific behaviour, depending on its physical properties: density, viscosity, interfacial tension. Therefore, the proposed demonstration is not universal and needs to be reinforced by testing other reaction systems.

Also, in addition to this interesting result, which is an incentive for promoting industrial enzymatic catalysis, it has been shown that the model reaction chosen here could also be a simple and elegant way to characterize mass transfer performance of these technologies. More precisely, it enables comparison of their ability to generate liquid-liquid dispersion and global assessment of the generated interfacial area. So, easy benchmarking can be proposed and may be an additional tool in the choice of the most suitable technology and optimal design and control of two-phase reactions performed in continuous mode.

\section{REFERENCES}

1 Slotema W, Sandoval G, Guieysse D, Strathof A and Marty A, Economically pertinent continuous amide formation by direct lipase-catalyzed amidation with ammonia. Biotechnol Bioeng 82:664-669 (2003).

2 Mbatia B, Adlercreutz P, Mulaa F and Mattiasson B, Enzymatic enrichment of omega-3 polyunsaturated fatty acids in Nile perch (Lates niloticus) viscera oil. Eur J Lipid Sci Technol 112:977-984 (2010).

3 Tweddell R, Kermasha S, Combes D and Marty A, Esterification and interesterification activities of a lipase produced by Rhizopus niveus in 3 different organic media: a comparative study. Enzyme Microbiol Technol 22:439-445 (1998).

4 Dossat V, Combes D and Marty A, Continuous enzymatic transesterification of high oleic sunflower oil in a packed bed reactor: influence of the production of glycerol. Enzyme Microbiol Technol 25:194-200 (1999).

5 Séverac E, Galy O, Turon F, Monsan P and Marty A, Continuous lipasecatalyzed production of esters from crude high-oleic sunflower oil. Bioresource Technol 102:4954-4961 (2011).

6 Barthe P, Guermeur C, Lobet O, Moreno M, Woehl P, Roberge DM, Bieler $\mathrm{N}$ and Zimmermann $\mathrm{B}$, Continuous multi-injection reactor for multipurpose production - Part I. Chem Eng Technol 31:1146-1154 (2008).

7 Zhang F, Cerato-Noyerie C, Woehl $P$ and Lavric ED, Intensified liquid/liquid mass transfer in Corning ${ }^{\circledR}$ Advanced-Flow ${ }^{\mathrm{TM}}$ reactors, in ICheaP-10 The tenth International Conference on Chemical and Process Engineering, 8-11 May 2011, Florence, Italy, (2011).

8 Chevalier B, Lavric ED, Cerato-Noyerie C, Horn CR and Woehl P, Microreactors for industrial multi-phase applications: test reactions to develop innovative glass microstructure designs. Chem Today 26:38-42 (2008).

9 Brocklehurst CE, Lehmann $\mathrm{H}$ and La Vecchia L, Nitration chemistry in continuous flow using fuming nitric acid in a commercially available flow reactor. Org Process Res Dev 15:1447- 1453 (2011).

10 Anxionnaz Z, Cabassud M, Gourdon C and Tochon P, Transposition of an exothermic reaction from a batch reactor to an intensified continuous one. Heat Transfer Eng 31:788-797 (2010).

11 Jia Z, Stryker LA and Decker DE, Plate fin fluid processing device. Patent US 20120016140 (2012).

12 Mackley MR and Ni X, Mixing and dispersion in a baffled tube for steady laminar and pulsatile flow. Chem Eng Sci 46:3139-3151 (1991).

13 Oliveira MSN and Ni X, Effect of hydrodynamics on mass transfer in a gas-liquid oscillatory baffled column. Chem Eng J 99:59-68 (2004).

14 Gómez-Quero S, Cárdenas-Lizana F and Keane MA, Liquid phase catalytic hydrodechlorination of 2,4-dichlorophenol over Pd/AI2O3: Batch vs Continuous operation. Chem Eng J 166:1044-1051 (2011).

15 Jones E, Mc Clean K, Housden S, Gasparini G and Archer I, Biocatalytic oxidase: batch to continuous. Chem Eng Res Des 90:726-731 (2012).

16 Sarda $L$ and Desnuelle $P$, Actions of pancreatic lipase on esters in emulsions. Biochim Biophys Acta 30:513-521 (1958).

17 Despènes L, Elgue S, Gourdon C and Cabassud M, Impact of the material on the thermal behaviour of heat exchangers-reactors. Chem Eng Process: Proc Int 52:102-111 (2012).

18 Marty A, Chulalaksananukul W, Willemot RM and Condoret JS, Kinetics of lipase-catalyzed esterification in supercritical $\mathrm{CO}(2)$. Biotechnol Bioeng 39:273-280 (1992).

19 Jealous AC and Johnson HF, Power requirements for pulse generation in pulsed columns. Ind Eng Chem 47:1159- 1166 (1955). 